\title{
TOWARDS A NEW SYSTEM OF HEALTH: THE CHALLENGE OF WESTERN DISEASE
}

\author{
Norman J. Temple, PhD; and Denis P. Burkitt, MD
}

\begin{abstract}
Over the last three decades, the concept of Western disease has become well established. Medicine has approached this group of diseases by searching for new cures but has achieved relatively little success. We argue that medicine should now accept the failure of this strategy and place a major emphasis on prevention. The key objective is to change the climate of opinion so that prevention is taken seriously by the general population. The chief activity should be a wide ranging public education campaign so as to persuade people to live a healthier lifestyle. Medicine will require restructuring in order to carry out this work. Medical education needs to be reformed so that medical students receive the necessary training. This must be done as part of an integrated approach in which government, industry and medical research all play a major role. Governments should use taxation and subsidies in areas such as food and tobacco so as to shift consumption patterns towards healthier products. Governments must also tighten laws on tobacco sales and advertising, support health education, and improve food labelling. Industry must be made far more responsive to the health needs of the population. This should be done both by public education, so as to alter demand, and by government action. Medical research should change its emphasis from studying the detailed mechanisms of disease ("complex research") to studying the role of lifestyle factors ("simple research").
\end{abstract}

\section{INTRODUCTION}

The last three decades have witnessed a tremendous change in our perception of medicine and disease. There are three major components of this:

1. The realization that the bulk of the chronic noninfective diseases (Western disease) is preventable.

2. The failure of medicine to significantly influence incidence rates for these diseases.

Norman J. Temple, PhD, Animal Sciences Division, Alberta Environmental Centre, Vegreville, Alberta TOB 4LO, Canada. He is Associate Professor of Nutrition, Athabasca University. Denis P. Burkit, MD, FRCS, FRS, Hartwell Cottage, Wells Road, Bisley, Glos GL6 7AG, England (U.K.).

Requests for reprints should be addressed to Dr. Norman J. Temple, Faculty of Science, Athabasca University, Box 10,000, Athabasca, Alberta T0G 2R0, CANADA.

(C) 1993 Human Sciences Press, Inc. 
3. The rapid pace of technological advances in medicine, but with the discovery of few effective cures.

Taken together these observations indicate that current approaches to the way we deal with disease are illogical. In this paper we make proposals for a new system centered on prevention.

\section{Western Disease and Prevention}

A convincing body of evidence has emerged which demonstrates that many of the diseases which plague Western societies must be preventable. Starting with the work of Trowell $^{1}$ and Cleave ${ }^{2}$, and subsequently Trowell and Burkitt ${ }^{3}$, we have the concept of Western disease. Based on epidemiology (i.e., comparative worldwide studies and the chronological emergence of these diseases) we now know that obesity, type II diabetes, coronary heart disease, appendicitis, cancer of the breast, lung, colon and prostate, and numerous other common diseases are direct consequences of the Western lifestyle. These diseases account for the bulk of noninfective disease in modern society.

Research has demonstrated the two areas of the Western lifestyle that are the dominant causative factors: diet and smoking.

\section{Medicine and Western Disease}

Medicine (by which we mean medical practice in general) has, in its approach to Western disease, been dominated by the search for new therapies. Thus, the areas of drug treatment and surgery, as well as disease diagnosis, have seen major developments in the last three decades. Medicine has proven to be an enthusiastic consumer of modern technology. Yet what is seldom appreciated is the extent to which genuine new cures have failed to appear.

Of course, several Western diseases can be successfully remedied; for instance, gallstones and appendicitis. However, in nearly all such cases the treatments have been around for over half a century. One notable area where effective new treatments have been developed for Western disease is in the area of diet therapy. Examples include type II diabetes and diverticular disease of the colon. However, these treatments center around the use of natural, particularly high fiber, diets. That is far removed from the conventional medical approach of drugs and surgery. We can point to extremely few instances where conventional medical progress over the last three decades has led to a significant improvement in the cure rate for a Western disease. New drug 
treatments for peptic ulcers (a partially Western disease) and hypertension are examples. But how many others are there? Even with hypertension, the situation leaves much to be desired; Smith et al $^{4}$ recently reported that in Scotland no more than a third of hypertensives have their condition both detected and treated satisfactorily.

Cancer also illustrates the point. Medicine routinely reports new "breakthroughs" and repeatedly states that survival times are continually improving. However, we ${ }^{5}$ have argued that a sober appraisal of the evidence points to, at best, a meagre improvement in cure rates for the major cancers. Therapeutic advances have been largely confined to the less common cancers, particularly those of children and young adults. Obesity provides another example. The cure rate (i.e. the numbers who achieve and maintain their ideal weight) is well known to be low.

Medicine is, of course, proficient at alleviating symptoms. Whether we are dealing with Western or with non-Western disease, medicine has an armoury of pain killers and other symptom alleviating weapons. It cannot be overstressed, though, that this does nothing to reduce the incidence of disease and contributes little to the overall health of a community.

The above arguments should not be taken as a denigration of the value of modern medicine. First, symptom alleviation, while only of tertiary importance to health (behind prevention and cure), is nonetheless important. Second, medicine is of tremendous value in infectious disease and various non-disease states, particularly obstetrics and accident medicine.

\section{The Crisis of Modern Medicine}

In the U.S.A. in 1970, medical expenditures consumed about eight percent of the Gross National Product (G.N.P.). By 1990 this had reached over twelve percent. In Britain, also, medicine shows an insatiable appetite for extra spending. However, government policies since 1980 have turned the crisis into one of underspending rather than of overspending. The philosophy on both sides of the Atlantic is that if only more money could be pumped into hospitals, doctors, operating rooms and the supporting technologies, not forgetting the quest for new drugs, then our health goals would somehow be achieved. The history of "health" services over the last three decades shows that this is an illusion.

It is a safe prediction that high-technology medicine will continue its relentless cost escalation. This may lead to improved diagnosis, 
more sophisticated surgery and so forth. But it will do little or nothing to reduce disease incidence. As a result the crisis of medicine seems destined to deepen.

A debate has been in progress for some years as to the relative merits of the U.S. type health care system versus the British or Canadian types. This debate is symptomatic of the crisis but in no way deals with the real issues. In all three countries, doctors busy themselves parking ambulances at the bottom of the cliff, not building fences at the top. For instance, it was estimated that in 1987 the U.S.A. spent less than 0.3 percent of its total health care expenditure on health promotion and disease prevention. ${ }^{6}$

The dominant health issue of today in industrialized populations is Western disease. Medicine has had little success in finding cures for this group of diseases. There is no reason to suppose that cures are just over the horizon. Yet, on the other hand, we already have a large reservoir of knowledge on how to prevent Western disease. Prevention is therefore the most practical strategy for the war on disease.

\section{Medicine: The Need for a New Strategy}

Firstly and foremost, medicine needs to accept its limitations. There should be far less boasting of "breakthroughs". Rather, medicine must freely admit that the accumulated effect of decades of medical advances is that only a small proportion of Western disease is curable. Hand in hand with this must come a hammering away at the point that these same diseases are preventable. This new realism will go far to change popular attitudes that the principle way to deal with disease is to sit back, wait for a disease to strike and then have a doctor pour chemicals down the esophagus.

The primary objective must be to change the climate of opinion. A useful model is recent developments on the environmental question. Because of successful public education, mainly via the mass media, there is now wide public support for protecting the environment, even if this causes much inconvenience and expense. We also see how the climate of opinion can be changed with the question of drinking and driving. Public education has made this much less socially acceptable and, consequently, many people do not commit this crime who otherwise might.

Central to medicine's strategy must be a wide ranging, long term campaign to persuade the general population to adopt a health lifestyle. The following must be prominent parts of it: 
a. When patients visit a doctor, the opportunity should be taken to emphasize the importance of a healthy lifestyle. Studies indicate that, for instance, when patients are advised by their doctor to quit smoking, a sigerant number do so. ${ }^{7,8}$ Of equal importance doctors must eapriasize sound nutrition to their patients.

b. Medicine should cooperate with education authorities so that health becomes a subject given serious attention in schools.

c. Campaigns should be carried out at the worksite to explain the benefits of a healthy lifestyle and to provide ongoing practical advice on how to carry this out.

d. Using the mass media must be given the highest priority. It is indisputable that the media have done vastly more to educate the public on health issues than has organized medicine.

There ara two major components of the message this campaign delivers:

a. Western diseases have a poor cure rate. Moreover, even when curable, prevention is far more desirable.

b. Lead a healthy lifestyle in order to prevent Western disease (i.e. eat a nutritious diet, don't smoke and take regular exercise). Of course, such areas as accidents and sexually transmitted diseases would also be discussed but these are outside the scope of this article.

Some might argue that it is unnecessary for organized medicine to engage in so much activity to deliver such a simple message, particularly when much of it is already well known. This would be an erroneous conclusion. First, there is still great ignorance of the relationship between diet and disease. For instance, in 1986 only 43 percent of U.S. adults could name fat as a cause of heart disease, while only 19 percent related fat to cancer. ${ }^{9}$ An additional reason medicine must take the lead in prevention is because only medicine carries the authority to persuade the general population of the importance of this message. In particular, medicine is uniquely well placed to shatter people's attitudes toward medicine itself.

Even where people are aware of the rudiments of staying healthy, far too few apply this knowledge. For instance, only a small minority of the middle-aged take more than a token amount of regular exercise. A recent dietary survey of American women indicated that 
whereas there was a shift between 1977 and 1985 towards food with a lower fat content, there is no evidence that a significant switch to foods rich in dietary fiber occurred. ${ }^{10}$ Americans are increasing their consumption of fruits and vegetables, but only at a snail's pace. ${ }^{9}$

From an organizational point of view, a great deal of work must obviously go into restructuring medicine to carry out its task. So far we have used the word "medicine" loosely. We envisage coordinated activities involving doctors, nurses, dietitians and other health-care professions. Quite likely a new class of health-care worker will have to be brought into existence to specialize in prevention. Such a prevention health-care worker will spend his or her time talking nutrition to office workers, discussing the consequences of cigarette smoking with teenagers, advising the slothful middle-aged how to exercise, and so forth. A fine example of worksite health promotion was implemented by the Johnson \& Johnson Company. ${ }^{11}$ So that doctors can fully play their part, they need to be trained in nutrition and other aspects of prevention. McPhee et $a^{12}$ recently reported on how this can be achieved. Most doctors are weak in that area. Obviously the appropriate training should be integrated into the medical curriculum. Alas, medical training is still dominated by diagnosis and treatment; it pays little attention to prevention and nutrition. ${ }^{6,13}$ Medical students must be given a thorough understanding of disease causation and the role of lifestyle factors. This should include nutrition taught in a meaningful and practical way (i.e. with an emphasis on the foods we should eat, not the vitamins). Medical students should also learn techniques of influencing behavior. It would be of great value if nurses, also, received the above training.

\section{The Role of Government}

It would be the height of naiveté to suppose that medicine on its own could bring about the required changes. Far from it: medicine's powers and resources are much too limited. A major responsibility lies with governments since they have considerable influence on public health through administrative, legislative and taxation policies.

Of course, most Western governments have declared prevention to be their aim. However, when we look more closely, we find that all too often governments are slow to move from rhetoric to action. This is well illustrated by tobacco. Virtually every government in the Western world has an "official" policy that people should smoke less, but in practice, set tobacco taxes at a level so as to maximize government revenues rather than to minimize sales. ${ }^{14-16}$ 
This sort of hypocrisy by many governments extends to matters of food policy. The National Advisory Committee on Nutrition Education (NACNE) scandal in Britain is a well known example. ${ }^{17}$ Cannon $^{18}$ gives numerous other examples where British governments have suppressed or distorted research findings so as to foster the illusion that the national diet is less awful than it really is.

For prevention to become the cornerstone of a new health system the philosophy that underlies the above scandals must radically change. The following are some of the more important suggested changes:

a. Taxation policies should be used to discourage the sale of unhealthy commodities, most notably cigarettes. Smokers typically start the habit as teenagers and at that age price has a major effect on consumption. Even with older smokers price increases cause a drop in sales. ${ }^{14,19}$ In other areas, also, taxation policies can be used to encourage healthy activities. For instance, removal of the tax on bicycles would not only encourage exercise but would also be helpful to the environment. Food policy is, of course, critically important. Governments should also consider a program of selective taxes and subsidies so as to shift consumption from, for example, fatty meats to lean and from white bread to whole wheat.

b. Governments can use their powers in other ways to encourage healthy eating (e.g. by banning advertisements for junk foods on children's TV programs and by insisting that school meals are based on sound nutrition.

c. Legislation needs to be brought in, where this has not yet been done, to ban all advertising for tobacco, including tobacco sponsorship of sport. Laws to prevent the sale of tobacco to young people must be tightened, particularly by banning vending machines and by imposing stiff fines on shops that sell cigarettes to children. There needs to be tighter controls against passive smoking as, for example, in offices, bars and restaurants.

d. Governments should encourage people to exercise. For instance, more sports facilities and bicycle lanes should be provided.

e. Governments should actively support health education, particularly by supplying funds and by encouraging its incorporation into the school curriculum. The need for such education was graphically illustrated by a recent survey in Florida. Only a small 
proportion of people could correctly answer simple nutrition questions. For instance, only one person in 30 had even a rough idea of the recommended intake of dietary fiber. Hospital nurses and support staff did not fare much better. The authors conclude that: ". . . information on food labels regarding fat, fiber, and recommended dietary allowances has little meaning to consumers". ${ }^{20}$

f. The laws governing food labelling need to be overhauled so as to give consumers an informed choice. A system using a standardized format and easily comprehensible to the lay person needs to be legislated to indicate the composition of manufactured food products, particularly for fat (total and saturated), sugar, fiber, salt and calories. Such a labelling system should, where feasible, be extended to the menu in fast-food outlets.

Issues linked to tobacco provide strong evidence for the potential effectiveness of government intervention. The fall in tobacco sales that follows a rise in price was noted above. Similarly, Pierce ${ }^{19}$ pointed out that when a country introduces a total ban on tobacco advertising there is a drop in consumption of about five percent the following year.

\section{Industry}

Like government, industry has a major impact on people's health. Through the composition of foods, advertising, pricing and so forth, it greatly affects what people eat and numerous other aspects of their environment and lifestyle. Alas, from the health viewpoint there is a great deal to be desired in the way industry conducts itself.

Industry is motivated primarily by profit, not people's health. We regularly see this when there is a conflict of interest between the health of the consumer and the health of the balance sheet. The rearguard action fought by the petrochemical industry to preserve the lead content of gasoline is a good example. ${ }^{21,22}$ Over the years the pharmaceutical industry has been the source of numerous scandals relating to highly dubious, often outright dishonest, marketing practices. ${ }^{23,24}$ For instance, in 1989 Yeltin $^{25}$, an official with the U.S. Food and Drug Administration (FDA), stated that the "vast majority" of promotional materials submitted for consideration by the FDA is false or misleading or both. Those parts of the food industry selling highly refined, fat-rich foods have shown little concern for the health effects of their products. Quite the opposite: aggressive advertising is as intense as ever. Tobacco is, of course, the extreme case. Few would disagree that tobacco manu- 
facturers would much rather let 10,000 healthy teenagers take the path to tobacco addiction and premature death than see their profits dip.

Often, however, industry is remarkably innovative and responsive to the health needs of the consumer. We see this in the appearance of low-calorie pop drinks, low-calorie margarine, skimmed milk, the reduced fat content of beef and the increased marketing of brown bread. We also see it in the radically improved exercise machines now available. However, in each of these cases industry has been motivated by market forces and new sales opportunities and not by the health needs of the consumer.

The above arguments point to another responsibility of governments: industry must be much more carefully regulated so that it acts in the interests of public health to the greatest extent possible.

\section{Medical Research}

Most medical research is what we term "complex research"5,26 as it investigates the detailed mechanisms of disease. This includes such areas as molecular genetics and the large majority of biochemistry and immunology. Despite utilizing the lion's share of research resources it has not told us how to deal with disease. A minority of research is "simple research" and focuses on environmental, particularly lifestyle, factors (diet, exercise etc.) in disease causation. Population studies, prospective and case-control studies and experimental intervention in humans or animals (e.g. testing whether a diet supplement will prevent a particular disease) are the major forms of simple research. The key feature of simple research is that the results are immediately and directly relevant to our understanding of the disease in question. Complex research, by contrast, provides huge numbers of small pieces of gigantic jigsaw puzzles. Resulting from this it is simple research that provides clear clues as to the factors which cause or prevent disease. Simple research seldom tells us how a disease comes about but it often tells us what we can do about it, particularly with respect to prevention.

\section{Prevention: an integrated approach}

The prevention of Western disease is the new frontier of medicine. The present situation is comparable to that existing in the last century when Pasteur discovered that germs cause much disease. Pasteur ran into considerable inertia from the conservative forces in medicine and government. History is already showing clear signs of repeating itself. 
The immediate task of medicine is to rethink its strategy. It is now generally accepted that Western disease is preventable: the challenge facing medicine is to move from a rearguard action to a grand offensive.

To be truly effective, a preventive campaign must involve government, industry and medical research. The change in public attitudes and behavior that is required is so profound that only when prevention functions as an integrated entity will real progress be made. Accordingly, structures need to be developed-government level committees, think tanks, research groups and so forth-which can develop concrete plans so that government, industry and medical research, as well as medicine, start to effectively work together towards the common goal. Of course, these proposals may well be premature by several years. Perhaps a more realistic primary objective is to change the thinking of those in government and medical research. That indicates another crucial and immediate task for medicine. Hopefully, the final decade of the millenium will see the implementation of proposals similar to those made in this paper.

\section{REFERENCES}

1. Trowell, HC: Non-infective disease in Africa. London: Edward Arnold, 1960.

2. Cleave, TL, and Campbell, BD: Diabetes, coronary thrombosis and the saccharine disease. Bristol: John Wright, 1966.

3. Trowell, HC, and Burkitt, DP: Western diseases: their emergence and prevention. London: Edward Arnold, 1981.

4. Smith, WCS, Lee, AJ, Crombie, IK, and Tunstall-Pedoe, H, Control of blood pressure in Scotland: the rule of halves. Br Med J 300:981-3, 1990.

5. Temple, NJ, and Burkitt, DP, The war on cancer: the failure of therapy and research. J R Soc Med 84:95-8, 1991.

6. Califano, JA, America's health care revolution: health promotion and disease prevention. J Am Diet Assoc 87:437-40, 1987.

7. Multiple Risk Factor Intervention Trial Research Group. Multiple risk factor intervention trial. Risk factor changes and mortality results. JAMA 248:1465-77, 1982.

8. Hjermann, I, Velve Byre, K, Holme, I, and Leren, P, Effect of diet and smoking intervention on the incidence of coronary heart disease. Report from The Oslo Study Group of a randomised trial in health men. Lancet ii:1303-10, 1981.

9. Bal, DG, and Foerster, SB, Changing the American diet. Impact on cancer prevention policy recommendations and program implications for the American Cancer Society. Cancer 67:2671-80, 1991.

10. Popkin, BM, Haines, PS, and Reidy, KC, Food consumption trends of U.S. women: patterns and determinants between 1977 and 1985. Am J Clin Nutr 49:1307-19, 1989.

11. Breslow, L, Fielding, J, Herrman, AA, and Wilbur, CS, Worksite health promotion: its evolution and the Johnson \& Johnson experience. Prev Med 19:13-21, 1990.

12. McPhee, SJ, Bird, JA, Fordham, D, Rodnick, JE, and Osborn, EH, Promoting cancer prevention activities by primary care physicians. JAMA 266:538-44, 1991.

13. Brett, A, Godden, DJ, and Keenan, RA, When and how should nutrition be taught to medical students? Proc Nutr Soc 45:13A, 1985. 
14. Godfrey, C, and Maynard, A, Economic aspects of tobacco use and taxation policy. Br Med J 297:339-43, 1988 .

15. Phillips, M, Why smoking not health wins the day. Guardian 1980 (6 May).

16. Leichter, H, Public policy and the British experience. Hastings Cent Rep 11(5):32-9, 1981.

17. Walker, C, and Cannon, G: The food scandal. London: Century Arrow, 1985.

18. Cannon, G: The politics of food. London: Century, 1987.

19. Pierce, JP, Progress and problems in international public health efforts to reduce tobacco usage. Ann Rev Publ Health 12:383-400, 1991.

20. Schapira, DV, Kumar, NB, Lyman, GH, and McMillan, SC, The value of current nutrition information. Prev Med 19:45-53, 1990.

21. Bryce-Smith, D, and Stephens, R, Lead and brain function. Dev Med Child Neurol 24:90-1, 1982.

22. Bryce-Smith, D, and Stephens, R: Lead or health-a review of contemporary lead pollution. London: Conservation Society, 1980.

23. Medawar, C: Drug disinformation. London: Social Audit, 1980.

24. Stimson, GV, Do drug advertisements provide therapeutic information? J Med Ethics 3:7-13, 1977.

25. Anonymous. FDA's drug problems. Scrip, World Pharm News No. 1389:14, 1989 (24 Feb).

26. Temple, NJ, Simplicity-the key to fruitful medical research. Med Hypotheses 17:139-45, 1985. 